\title{
Effect of Lithium Chloride on the Fibre Length Distribution, Processing Temperature and the Rheological Properties of High-Yield-Pulp-Fibre-Reinforced Modified Bio-Based Polyamide 11 Composite
}

\author{
Robenson Cherizol1,2,3*, Mohini Sain1,3, Jimi Tjong2 \\ ${ }^{1}$ Centre for Biocomposites and Biomaterials Processing, Faculty of Forestry, University of Toronto, Toronto, Canada \\ ${ }^{2}$ Powertrain Engineering Research \& Development Centre, Ford Motor Company, Windsor, Canada \\ ${ }^{3}$ Department of Chemical Engineering \& Applied Chemistry, University of Toronto, Toronto, Canada \\ Email: *robenson.cherizol@mail.utoronto.ca
}

How to cite this paper: Cherizol, R., Sain, M. and Tjong, J. (2017) Effect of Lithium Chloride on the Fibre Length Distribution, Processing Temperature and the Rheological Properties of High-Yield-Pulp-FibreReinforced Modified Bio-Based Polyamide 11 Composite. Advances in Nanoparticles, 6, 48-61.

https://doi.org/10.4236/anp.2017.62005

Received: July 18, 2016

Accepted: April 10, 2017

Published: April 13, 2017

Copyright $\odot 2017$ by authors and Scientific Research Publishing Inc. This work is licensed under the Creative Commons Attribution International License (CC BY 4.0).

http://creativecommons.org/licenses/by/4.0/

cc) (†) Open Access

\begin{abstract}
The aim of this work was to investigate the effect of lithium chloride ( $\mathrm{LiCl}$ ) on the fibre length distribution, melting temperature and the rheological characteristics of high yield pulp fibre reinforced polyamide biocomposite. The inorganic salt lithium chloride ( $\mathrm{LiCl}$ ) was used to decrease the melting and processing temperature of bio-based polyamide 11 . The extrusion method and Brabender mixer approaches were used to carry out the compounding process. The densities and fibre content were found to be increased after processing using both compounding methods. The HYP fibre length distribution analysis realized using the FQA equipment showed an important fibre-length reduction after processing by both techniques. The rheological properties of HYP-reinforced net and modified bio-based polyamide 11 "PA11" (HYP/PA11) composite were investigated using a capillary rheometer. The rheological tests were performed in function of the shear rate for different temperature conditions. The low-temperature process compounding had higher shear viscosity; this was because during the process the temperature was low and the mixing and melting were induced by the high shear rate created during compounding process. Experimental test results using the extrusion process showed a steep decrease in shear viscosity with increasing shear rate, and this melt-flow characteristic corresponds to shear-thinning behavior in HYP/PA11, and this steep decrease in the melt viscosity can be associated to the hydrolyse reaction of nylon for high pulp fibre moisture content at high temperature. In addition to the low processing temperature, the melt viscosity of the biocomposite us-
\end{abstract}


ing the Brabender mixer approach increases with increasing shear rate, and this stability in the increase even at high shear rate for high pulp moisture content is associated to the presence of inorganic salt lithium chloride which creates the hydrogen bonds with pulp during the compounding process.

\section{Keywords}

HYP/PA11, Melting Temperature of Nylon 11, Inorganic Salt Chloride Lithium (Licl), Fibre Aspect Ratio and Length Distribution, Rheological Characteristic

\section{Introduction}

Short-fibre reinforced polymer composites are extensively used in manufacturing industries due to their light weight and improved mechanical properties [1] [2]. Hence, HYP has been used not only for its low lignin content, but also for its potential thermal stability and its strong adhesion when it is bonded with hightemperature engineering thermoplastic polymers [3] [4] [5] [6].

Various experimental studies have investigated the effect of flexibility on fluid viscosity. They concurred that the more flexible the fibres are, the more pronounced their effect on the rheological characteristics is [7] [8] [9]. A recent study on the effect of fibre-length distribution on the rheological behavior of castor-oil composite showed that at high fibre length, the shear viscosity becomes more dependent on shear rate [10]. This behavior is due to elastic deformation of the fibres [10].

Recently, various authors have investigated the effect of fibre content on polymer melt rheology [11] [12] [13]. Their study showed an important increase in shear viscosity with increased fibre loading at low shear rates, but only a small increase in viscosity at high shear rates [12] [13]. Another similar study on polypropylene-based long fibre observed an increase in shear viscosity with increased fibre content and fibre length [13]. However, this viscosity rise was very small, which the authors attributed to high shear rates and fibre breakage during the processing [13] [14]. Non-Newtonian fluid characteristics such as shear thinning were also observed in all the studies mentioned above.

There is only a very limited literature devoted to experimental studies of the rheology of pulp-fibre-reinforced polymer composites due to the complex nature of these materials and the difficulties encountered during their processing and their rheological characterization [13] [14] [15] [16] [17].

The processing technique and conditions have a significant influence on the rheological and overall properties of pulp-fibre-reinforced polymer composites because they dictate the degree of dispersion and distribution of the fibre in the polymer matrix and the low processing temperature required in order to avoid thermal degradation [18] [19] [20] [21]. Compared to other natural fibres, HYP is more thermally stable in the presence of high-melting-temperature engineer- 
ing thermoplastics (under $180^{\circ} \mathrm{C}$ ) such as PA11, PA6, and PA66.

The principal objectives of the study described in this chapter were to determine the effect of the addition of the inorganic salt lithium chloride ( $\mathrm{LiCl}$ ) to the bio-based polyamide 11, and the characteristic of the modified bio-based polyamide 11 in the presence of high yield pulp (HYP) fibre. The HYP fibre content, the length distribution, and the density of the composites were measured and analyzed for both processing techniques in order to investigate the effect of $\mathrm{LiCl}$ on the composite components. Finally, the rheological results using the Brabender mixer technique and the conical twin extruder respectively were determined and compared.

\section{Material and Methods}

\subsection{Materials}

The matrix biopolymer bio-based polyamide 11 , density 1.03 , MFI 11, was supplied by Arkema (France). Aspen high yield pulp (HYP) fibres were supplied by Tembec (Montreal, QC). The HYP is the type used in wood-free printing, in writing-paper grades and in multiple-coated folding-board grades; fibre length is 0.230 to $0.85 \mathrm{~mm}$.

\subsection{Methods}

\subsubsection{Composites Preparation}

The experiment was processed using a conical twin screw extruder and a Brabender mixer technique. In both mixing processes, the high yield pulp "HYP" fibre was dried at $80^{\circ} \mathrm{C}$ for 6 hours and then added to the corresponding bio-based polyamide PA11 and well mixed before the combination was introduced to the extruder. The average temperature of the barrel was $200^{\circ} \mathrm{C}$. Figure 1 represents the different zones of the conical twin-screw extruder. In addition, in the Brabender mixer technique process, different lithium chloride content "LiCl" was added to the bio-based polyamide 11 at corresponding process temperature prior to adding the pulp fibre.

\subsubsection{Effect of Processing Conditions}

Many processing parameters affect the properties of final products. For extrusion, temperature profiles affect the fibre degradation. In addition, screw speed

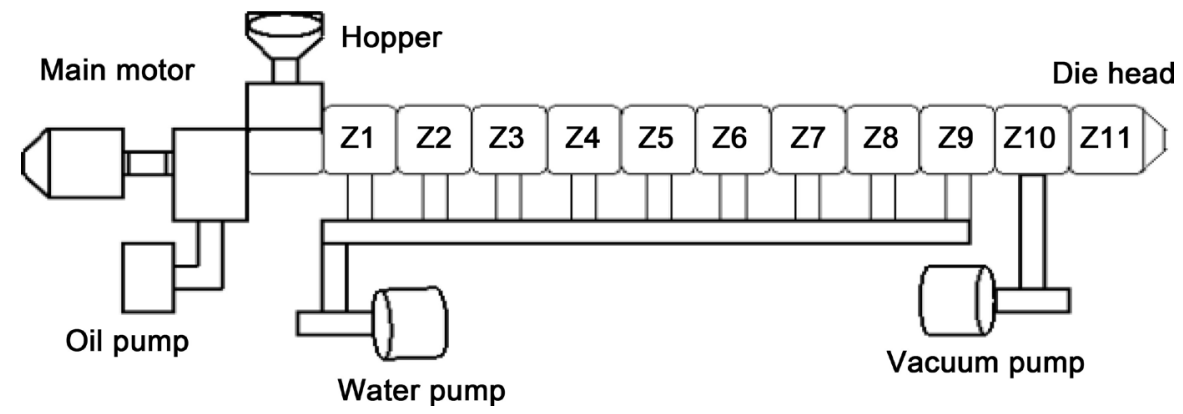

Figure 1. Schematic figure of twin-screw extruder. 
Table 1. Extrusion temperature profile for $10 \%, 20 \%$ and 30\% HYP/PA11, $120 \mathrm{rpm}$ (10\% and $20 \%), 130 \mathrm{rpm}(30 \%)$ and $10 \mathrm{rpm}$ feed rate.

\begin{tabular}{cccccccccc}
\hline \multicolumn{10}{c}{ Temperature $\left({ }^{\circ} \mathrm{C}\right)$} \\
\hline Zone 1 & Zone 2 & Zone 3 & Zone 4 & Zone 5 & Zone 6 & Zone 7 & Zone 8 & Zone 9 & Zone 10 \\
\hline 200 & 200 & 200 & 200 & 200 & 205 & 205 & 205 & 205 & 205 \\
\hline
\end{tabular}

and feeding rate change fibre length, distribution, and orientation. The mechanical properties reflect all these changes, and the processing parameters are optimized to obtain the best properties. Table 1 represents the processing parameters for HYP/PA11 used in this study.

However, the Brabender mixer technique was used as the principal compounding process in this study. Inorganic salt lithium chloride $(\mathrm{LiCl})$ was added to bio-based polyamide 11 in order to decrease it melting temperature, and consequently avoid fibre degradation and burning. Different lithium chloride content was used to reduce the melting temperature of polyamide 11 using the Brabender mixer technique.

\subsubsection{Fibre Content and Length Distribution Analysis after Compounding} The composite samples were cut into small pieces and immersed in formic acid for three days. The bio-based PA11 was dissolved by the formic acid and HYP was left. The HYP was filtered and washed with formic acid, then dried in a vacuum oven for four hours. By measuring the weight of composite and pulp fibre, we could calculate the actual fibre content.

HYP fibre length was measured with the Fiber Quality Analyzer (FQA). The HYP was diluted with D.I. water. The diluted HYP fibre entered a thin-planar channel. This channel helped to gently orient the fibre 2-dimensionally, so that the fibre could be fully viewed by the camera. The picture taken by the camera was then analyzed by the software to give the HYP fibre length distribution.

\subsubsection{Actual Density Measurement}

The density of polyamide 11 reinforced HYP fibre composites was determined by using the ASTM D792 technique. The samples were first weighed both in water and air, and then the density was calculated by:

$$
\rho=a /\left[(a-w) \rho_{\text {water }}\right]
$$

where $\rho$ is the sample density in $\mathrm{g} / \mathrm{cm}^{3}, a$ is the sample weight in air in $\mathrm{g}, W$ is the sample weight in water in $\mathrm{g}$, and $\rho_{\text {water }}$ is the density of the water in $\mathrm{g} / \mathrm{cm}^{3}$.

\subsubsection{Differential Scanning Calorimetry (DSC)}

The melting temperature and crystallization behavior of the yield pulp fibre reinforced bio-based polyamide 11 composites were investigated using a TA instrument Q1000 differential scanning calorimeter (DSC) attached to a cooling system under a nitrogen atmosphere. The DSC instrument was run from $45^{\circ} \mathrm{C}$ to $250^{\circ} \mathrm{C}$ with a heating rate of $10^{\circ} \mathrm{C} / \mathrm{min}$. The sample weight was about $5 \mathrm{mg}$. 
The specimens were sealed in aluminum pans by pressing and the prepared samples were placed in the furnace of DSC with an empty reference pan. The heat flow rate as function of temperature was recorded automatically. Melting temperature was identified on the peak point of the DSC curves. The melting of polymer within a composite system would assist to select a suitable temperature profile for the compounding process technique when the fibres and matrix were compounded to produce green composite.

\subsubsection{Rheological Properties Measurement}

The rheological measurements of the composites' melt-flow properties of were carried out in a twin-bore Rosand Capillary Rheometer model RH2000. (The standard $\mathrm{RH} 2000$ range supports temperatures from $-40^{\circ} \mathrm{C}$ to $500^{\circ} \mathrm{C}$. The standard maximum force applied is $12 \mathrm{kN}$.) The composite samples for testing were cut into very small pieces, then placed inside the barrel and forced down into the capillary with the plunger attached to the moving cross-head. Representative steady-shear viscosity versus high shear rate is presented in the figures below for $\mathrm{HYP} / \mathrm{PA} 11$, which was processed at the average extrusion temperature of $200^{\circ} \mathrm{C}$. The viscosity of the sample was obtained from steady-shear measurements for different temperature profiles, with the rate ranging from 50 to $5000 \mathrm{~S}^{-1}$. The rheological viscosity data presented in this chapter thus represents an average value of three measurements.

\section{Results and Discussion}

\subsection{Effect of the Lowering the Processing Temperature on the Pulp Fibre Distribution and the Bio-Based Polyamide Density after Processing}

To avoid the degradation of the HYP fibre during the processing of the composite, decreasing the melting temperature was attempted. The reduction of the melting point of high-temperature-engineering polyamide was realizing by the utilization of inorganic salt during the melt compounding processing in order to lower the melting temperature of polyamide 11 (PA11). Lithium chloride ( $\mathrm{LiCl}$ ) was added to the polyamide 11 during the extrusion process using the Brabender mixer technique. Next, the PA 11 and salt mixture was used as a matrix and HYP fibre was incorporated into the matrix using a Brabendermixer for the compounding.

The melting temperatures of the PA $11 / \mathrm{LiCl}$ mixture are shown in Table 2. Table 3 shows the heat deflection temperatures of the PA11 polymer-reinforced HYP fibre composites. $3 \% \mathrm{LiCl}$ in PA11 was chosen in order to keep the concentration of $\mathrm{LiCl}$ low. From $3 \%$ to $5 \% \mathrm{LiCl}$ in the PA11, the change in melting temperature is insignificant. The stability of the melting point at high $\mathrm{LiCl}$ concentration is due to the lowering of the crystallization temperature and the saturation of the degree of crystallinity of the molecular chains.

The heat deflection temperature was investigated for only $3 \% \mathrm{LiCl}$ content. The addition of $\mathrm{LiCl}$ to PA11 decreases the crystallization temperature and degree of crystallinity. Consequently, the heat deflection temperature of PA11 de- 
Table 2. Melting temperatures of neat PA11 and modified PA11 with varying $\mathrm{LiCl}$ content.

\begin{tabular}{cc}
\hline Composition & Melting temperature $\left({ }^{\circ} \mathrm{C}\right)$ \\
\hline Neat Polyamide (PA11) & 188 \\
PA11 + $\%$ LiCl & 186 \\
PA11 + $\%$ LiCl & 182 \\
PA11 + $\%$ LiCl & 175 \\
PA11 + $\%$ LiCl & 172 \\
PA11 + 5\%LiCl & 170 \\
\hline
\end{tabular}

Table 3. Heat deflection temperatures of polyamide 11 and HYP-fibre-reinforced biobased PA11 composites.

\begin{tabular}{cc}
\hline Composition & Heat deflection temperature $\left({ }^{\circ} \mathrm{C}\right)$ \\
\hline Neat PA11 & 135 \\
PA11 + 3\%LiCl & 52 \\
PA11 + 3\%LiCl + 10\% HYP fibre & 118 \\
PA11 + 3\%LiCl + 20\% HYP fibre & 126 \\
PA11 + 3\%LiCl + 30\% HYP fibre & 138 \\
\hline
\end{tabular}

creased from $135^{\circ} \mathrm{C}$ to $52^{\circ} \mathrm{C}$ of neat PA 11 . However, with the addition of $10 \%$ HYP fibre, the heat deflection temperature (HDT) increased to as high as $118^{\circ} \mathrm{C}$. For $30 \%$ HYP added to the modified PA11, the heat deflection temperature rises up to $138^{\circ} \mathrm{C}$. The higher is the content of the pulp fibre, the higher is the heat deflection temperature of the composite. The increase in the heat deflection temperature (HDT) of the resultant composite is proportional to the concentration of high yield pulp fibre to the modified PA11 and LiCl.

\subsection{Densities and Actual Fibre Contents}

The fibre contents of composites were controlled by the feeding rate of matrix and fibre. However, the feeding rate cannot be calibrated precisely, especially the feeding rate of HYP fibre. Table 4 shows the densities and actual fibre contents of composites processed by the extrusion compounding method and the Brabender mixer technique.

Comparing the densities of bio-based polyamide 11 reinforced HYP composites made by the two procedures, we can see that the composites made by the Brabender mixer technique have higher density than composites made by the extrusion process at the same fibre content. The 30\% HYP/PA11 made via the Brabender mixer has a higher density because its actual fibre content is $5 \%$ higher than the composite made by the extrusion process. The different densities show that Brabender mixer technique gives samples with fewer voids than the extrusion process.

The modified bio-basedPA11 reinforced HYP fibre composites have higher densities than the regular bio-based PA11-reinforced HYP fibre composites at 
Table 4. Densities and actual high-yield fibre contents.

\begin{tabular}{ccc}
\hline & Densities $\left(\mathrm{g} / \mathrm{cm}^{3}\right)$ & Actual pulp fibre content \\
\hline Polyamide 11 (PA11) reinforced & HYP & fibre composite: Extrusion compounding technique \\
\hline PA11 & 1.03 & 0 \\
PA11 + 10\% HYP & 1.05 & $12.5 \%$ \\
PA11 + 20\% HYP & 1.07 & $25 \%$ \\
PA11 + 30\% HYP & 1.12 & $33.2 \%$ \\
\hline Modified Polyamide 11 (PA11) reinforced & HYP fibre composite: Brabender mixer technique \\
\hline PA11 + 3\%LiCl + 10\% HYP & 1.07 & $14 \%$ \\
PA11 + 3\%LiCl + 20\% HYP & 1.11 & $26 \%$ \\
PA11 + 3\%LiCl + 30\% HYP & 1.21 & $38.3 \%$ \\
\hline
\end{tabular}

the same fibre content even though the modifiedPA11 has a slightly higher density than regular PA11. The reduction of the melting point, thus viscosity, could lead to a better fibre-matrix wetting to eliminate free volume, holes/voids in the biocomposite with $\mathrm{LiCl}$.

To minimize fibrethermal degradation, the processing temperature was set just below the commercial melting temperature of polyamide. Table 4 shows that the densities and actual fibre contents were proportional to the fibre content for both processing methods. However, with the addition of $\mathrm{LiCl}$ to the Brabender mixer, the differences became more pronounced.

\subsection{Effect of Fibre Content on the Length and Shape Distribution on HYP-Reinforced Bio-Based Modified PA11 Composite}

During the extrusion process, the shear stress applied by the screw breaks the fibres. The resulting fibre lengths affect the ultimate mechanical properties. In spite of the influence of fibre damage and breakage during processing, the initial fibre length in the feedstock determined the final fibre lengths. It was therefore important to analyze the initial fibre-length distribution, which is one of the most significant parameters for natural fibre reinforced polymer composites. After the polymer and fibre for the composite are decided on, fibre length is the adjustable feature used to manage the ultimate properties of bio-composite materials. Table 5 shows the results of HYP fibre length distribution determined using a Fibre Quality Analyzer (FQA).

The arithmetical length and the length-weighted values of HYP fibre length were found to be $0.20 \mathrm{~mm}, 0.27 \mathrm{~mm}$, and 0.49 respectively for the pulp fibres from 30\% HYP/PA11. The arithmetic and length-weight measured values for $20 \%$ of pulp fibre were $0.24 \mathrm{~mm}$ and $0.36 \mathrm{~mm}$, and for $10 \%$ pulp fibre they were $0.29 \mathrm{~mm}$ and $0.41 \mathrm{~mm}$. Most of the fibre lengths lie within the range of $0.20 \mathrm{~mm}$ to $0.57 \mathrm{~mm}$, since HYP fibre was used in this study. To obtain these average fibre lengths, 1500 single fibres were examined. The measured initial fibre length is greater than the actual length of the fibres in the composites. The HYP fibre length decreases inversely with the increase of pulp fibre content in the compos- 
Table 5. Fibre length distribution of pulp fibre (extrusion compounding process).

\begin{tabular}{cccc}
\hline \multirow{2}{*}{ Fibre } & \multicolumn{3}{c}{ Mean Length (measured) } \\
\cline { 2 - 4 } & Arithmetic $(\mathrm{mm})$ & Length weight $(\mathrm{mm})$ & Weight weighted $(\mathrm{mm})$ \\
\hline Only HYP & 0.38 & 0.57 & 0.73 \\
HYP (10\%) & 0.29 & 0.41 & 0.63 \\
HYP (20\%) & 0.24 & 0.36 & 0.54 \\
HYP (30\%) & 0.20 & 0.27 & 0.49 \\
\hline
\end{tabular}

Table 6. Fibre length distribution of pulp fibre (Brabender mixer approach).

\begin{tabular}{cccc}
\hline \multirow{2}{*}{ Fibre } & \multicolumn{3}{c}{ Mean Length (measured) } \\
\cline { 2 - 4 } & Arithmetic $(\mathrm{mm})$ & Length weight $(\mathrm{mm})$ & Weight weighted $(\mathrm{mm})$ \\
\hline \multicolumn{3}{c}{ Modified Bio-based PA11-HYP fibre composite: Brabender } & mixer technique \\
Only HYP & 0.38 & 0.57 & 0.73 \\
HYP (10\%) & 0.33 & 0.46 & 0.68 \\
HYP (20\%) & 0.28 & 0.38 & 0.60 \\
HYP (30\%) & 0.26 & 0.35 & 0.56
\end{tabular}

ite. This decrease of fibre length with the pulp fibre content in the polymer melt concentration is due to fibre entanglement and agglomeration within the polymer.

Table 6 shows that the HYP fibre length from the green composite produced using the Brabender mixer technique did not decrease very much compared with the HYP fibre length of the composite made using the conical twin extruder method. For modified bio-based PA11-reinforced pulp fibre bio-composites processed using the Brabender mixer technique, the mean fibre length did not decrease a great deal. In the normal bio-based PA11 reinforced HYP fibre composites, the HYP fibre length is shorter than that of the bio-based modified polyamide reinforced pulp fibre after extrusion, probably because the higher temperature caused more thermal degradation of fibres, making them easier to break. In addition, the use of $\mathrm{LiCl}$ to decrease the melting temperature of the bio-based PA11 may also have protected the pulp fibre from degradation and entanglement during the slow and controlled process using the Brabender mixer technique, and consequently kept the pulp fibre length constant after the compounding process.

\subsection{Rheological Characteristics of HYP-Reinforced Bio-Based Polyamide}

As already noted, rheological characteristics of the polymer, fibre, and interphasial phases influence the final characteristics of the resultant microstructure of the composite materials; these characteristics in turn affect the mechanical properties of a multiphase polymer-composite system. As obtained from experiment, the shear viscosity as a function of the steady-shear rate of HYP/PA11 at $200^{\circ} \mathrm{C}$ is shown in Figure 2 (As noted, these results are the average of three 


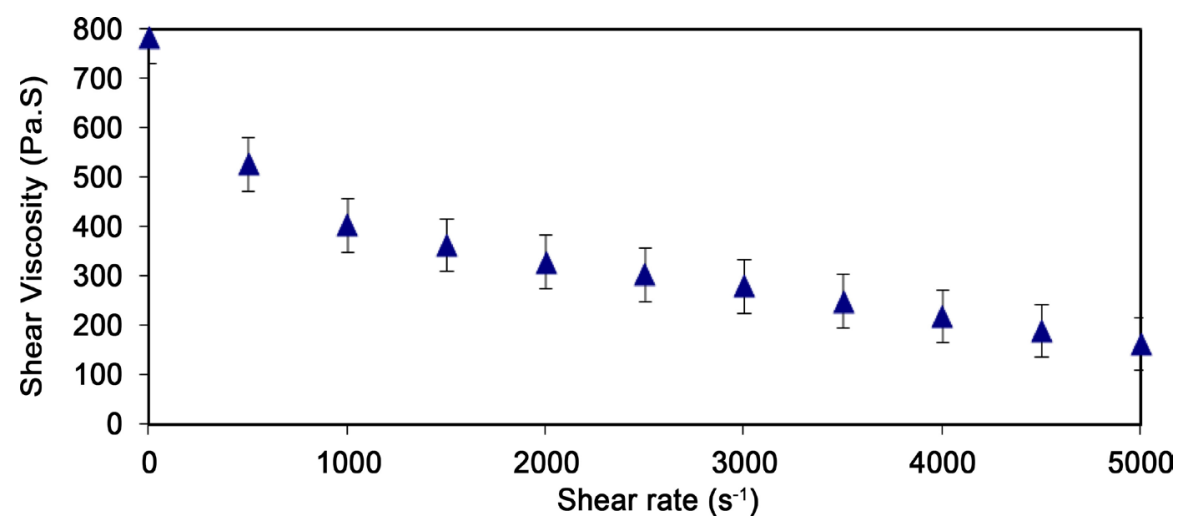

Figure 2. Shear viscosity vs. shear rate of $\mathrm{HYP} / \mathrm{PA} 11$ at $200^{\circ} \mathrm{C}$.

different experimental tests.)

As noted, the composite material used in the experimental study had an average fibre length of $0.73 \mathrm{~mm}$, and the experiment was conducted at $200^{\circ} \mathrm{C}$. The experimental results showed that the viscosity of HYP/PA11 composite decreases with increasing shear rate. This decrease in the shear viscosity with the increase of the shear rate corresponds to the pseudoplastic fluid characteristic of the composites. This pseudoplastic behavior (also referred to as shear-thinning behavior) as plotted in Figure 2 is mainly influenced by the orientation of the polymer molecules, the agglomeration of the flexible pulp fibre, and the entanglements within the polymer chains in the capillary rheometer. The chain agglomerations are produced simultaneously, as one chain is collapsed into another chain. The entanglements that lead to agglomerations of the chains, as well as the entanglements within the chains, are caused by the Brownian motions and low relaxation of HYP fibre. The high shear-thinning behavior obtained for HYP/PA11 can be also associated to the thermal degradation of HYP during the rheological testing and the compounding process. The molten polymers tend to arrange themselves with their major axes in the direction of shear, whereby points of entanglement are reduced. As a result, the viscosity decreases. In other words, in this instance of non-Newtonian flow behavior in polymer melts, the decrease in viscosity when the shear rate is increased by applying load is associated with high shear-thinning behavior and with viscoelastic characteristics of biocomposite materials. However, at very high shear rates (from 3000 to 5000 $\mathrm{S}^{-1}$ ) the molten HYP/PA11 showed a less restrained decrease in viscosity. This non-Newtonian behavior is associated with the alignment and orientation of the fibre in the polymer chains and the effect of the fibre aspect ratio. Both at low and high shear rates the formation of agglomerates is evident; therefore, the pulp molecules are completely oriented due to the good dispersion in the bio-based PA11 matrix. This means that the breakage of the fibre length allows the maintenance of an accurate fibre-aspect ratio when the diameter of flexible HYP is kept unchangeable during the process. The shorter length of the fibres also supports their alignment in the direction of the flow, thus reducing the fibre-fibre collisions and leading to a greater decrease in apparent viscosity. 


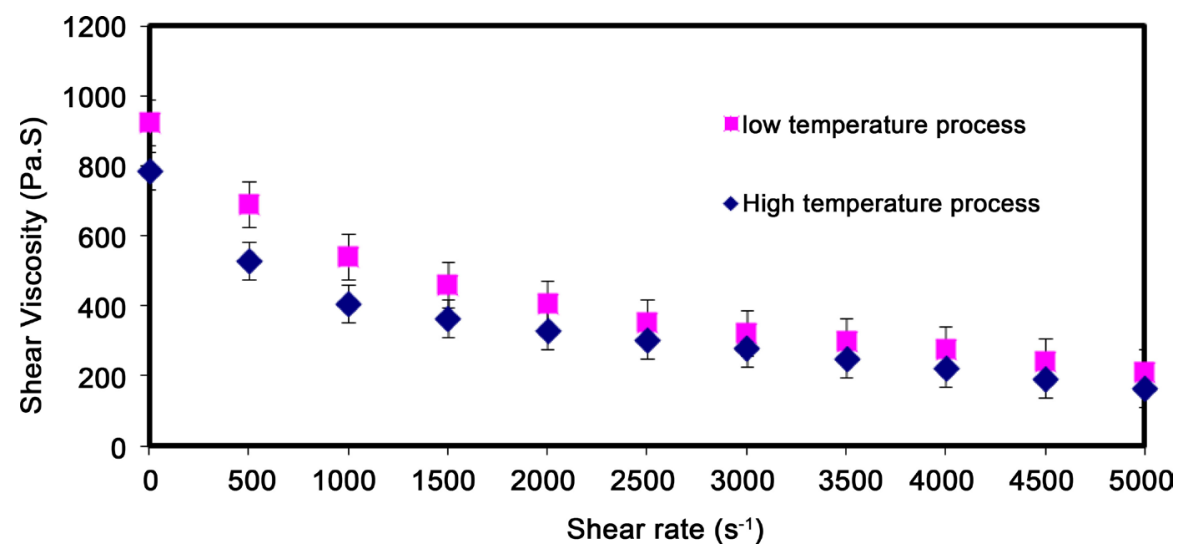

Figure 3. Shear viscosity vs. shear rate of HYP/PA11 at $200^{\circ} \mathrm{C}$.

\subsection{Effect of the Processing Parameters on the Rheological Property}

The rheological testing results for the different processing techniques (the extrusion process for the high temperature process, and the Brabender mixer method for the low temperature process) are presented below in Figure 3. The goal of decreasing the process temperature was only realized for 30\% HYP/PA11. The Brabender mixer approach was used for the low-temperature compounding, and the process temperature was below the melting point. The rheological properties of the high- and low-temperature compounding are presented in Figure 3.

The low-temperature process compounding has higher shear viscosity compared to the high temperature process; this is because a) during the low-temperature process the polymer melting was generated by the high shear rate created during compounding and also because the mixing process was incomplete.

\subsection{Effect of the Inorganic Salt Lithium Chloride on the Rheological Properties of HYP Fibre-Reinforced Bio-Based Polyamide Composite}

Variations in shear viscosity as a function of the shear rate of HYP/PA11 at various processing temperatures using inorganic salt $(\mathrm{LiCl})$ was realized in order to investigate their effect on the melting point and the rheological properties HYP-fibre-reinforced bio-based PA11 composite. The addition of inorganic salt lithium chloride to PA11 modified it melting point and consequently modified the processing temperature. The rheological test results are presented in Figure 4 and were achieved using the Brabender mixing technique. The processing conditions were $200^{\circ} \mathrm{C}$ for the net polyamide without $\mathrm{LiCl}, 186^{\circ} \mathrm{C}$ for $1 \% \mathrm{LiCl}$, $182^{\circ} \mathrm{C}$ for $2 \% \mathrm{LiCl}, 175^{\circ} \mathrm{C}$ for $3 \% \mathrm{LiCl}, 172^{\circ} \mathrm{C}$ for $4 \% \mathrm{LiCl}$, and $170^{\circ} \mathrm{C}$ for $5 \% \mathrm{LiCl}$ content. In this chapter, $\mathrm{LiCl}+$ bio-based PA11 " $\mathrm{LiCl}+\mathrm{PA} 11^{\prime}$ " is referred to as "modified" polyamide 11 for brevity. The rheological test results presented in the figure below are for constant fibre content $(30 \%)$ and for various process temperature and lithium chloride concentrations.

The variation in the shear viscosity of the HYP/PA11 in function of the rate of shear and lithium chloride concentration was measured and presented. The 


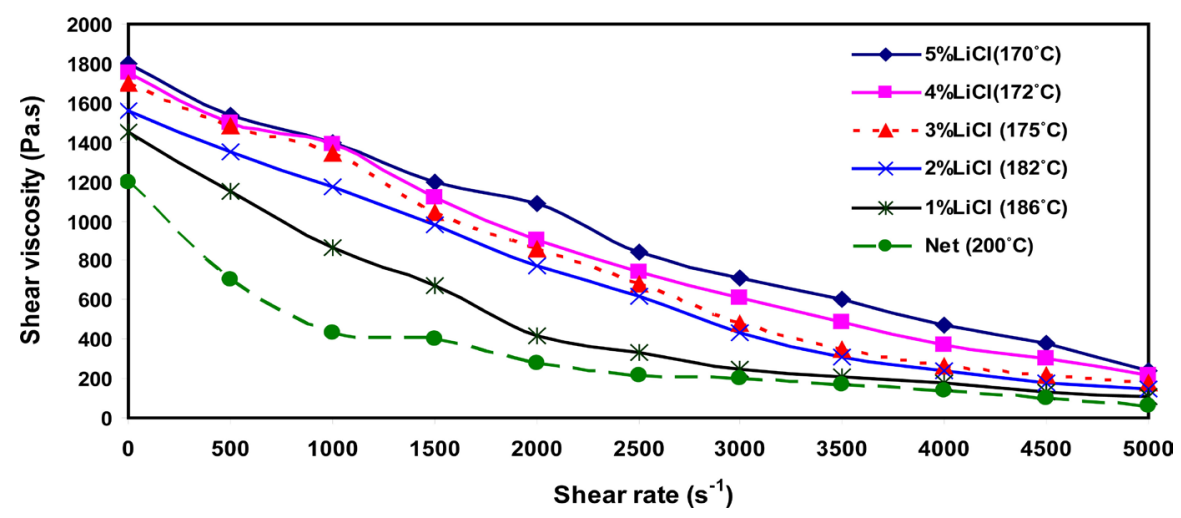

Figure 4. Variation of the viscosity with a function of shear rate of HYP/PA11 at various temperatures.

shearing effects decreased as the salt concentration increased: that is, the modified HYP/PA11 became more non-Newtonian in the higher temperature region for low $\mathrm{LiCl}$ concentration. At higher salt concentration the reduction of shear viscosity was more pronounced at intermediate shear rate, while for $175^{\circ} \mathrm{C}$, this reduction is maximized at higher shear rates (from 3000 to $5000 \mathrm{~S}^{-1}$ ). At low salt concentration and net processing temperature $\left(200^{\circ} \mathrm{C}\right)$ and for low and intermediate shear rate, the flow deformation is challenging. This is due to the fact that the HYP-reinforced PA11 fibres are entangled and agglomerated. At this point, such rheological behavior is called Near-Newtonian. At high shear rate, the shearing effects increased while the effect of temperature and the salt concentration were less pronounced, and flow deformation was mostly dominated by the shearing effect. However, from 3000 to $5000 \mathrm{~S}^{-1}$ all the shear-viscosity variations in function of shear rates followed the same rate of deformation for different salt content and temperature profiles, which corresponds to shear-thinning behavior.

\subsection{Effect of HYP Fibre Content on the Rheological Characteristics of Modified Bio-Base (PA11 + 3\%Licl) Composite}

The effect of fibre content on the rheological characteristics of the HYP-fibrereinforced modified bio-based polyamide composite was investigated. Figure 5 shows the experimental results for 10\%, 20\%, and 30\% HYPP reinforced modified PA11 "PA11 + LiCl". These curves are typical of pseudoplastic materials, which show a decrease in viscosity with increasing shear rate. At high fibre content, the material offers higher shear viscosity even for high shear rate. In general, the incorporation of fibres in polymer systems increases the viscosity, which rises further as fibre content is increased.

The difference between $10 \%$ and $20 \%$ fibre at intermediate and high shear rate is not very significant. At low HYP content, shear viscosity is expected to rise rapidly with increasing concentrations of fibre because of the rapidly increasing interactions between particles as they become more closely packed and entangled. Nevertheless, at very high pulp fibre concentration, random anisotropic structures of the fibres in polymer melts were created, and they increased the 


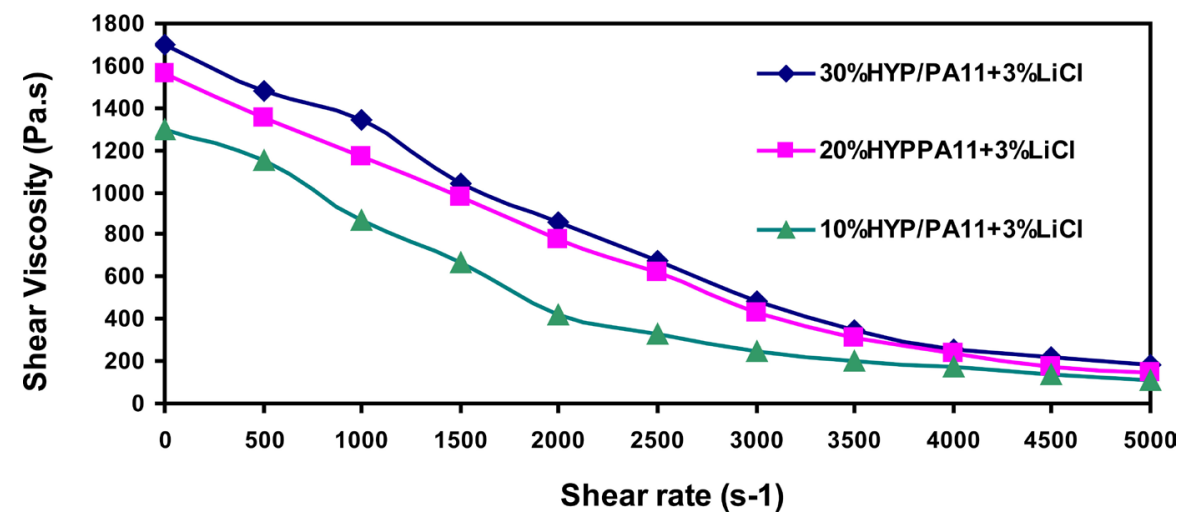

Figure 5. Shear viscosity vs. shear rate of HYP/PA11 at $200^{\circ} \mathrm{C}$.

shear viscosity. The increase in shear viscosity is found to be more predominant at lower shear rates, where fibre and polymer molecules are not completely oriented.

\section{Conclusions}

This study demonstrates that it is possible to process HYP fibre with highthermoplastic-engineering bio-based polyamide. For both processing methods and all formulations, fibres showed a length reduction after compounding process. The observed fibre length reduction using the extrusion process method was lower compared to the fibre length reduction using the Brabender mixer technique. However, the highest fibre reduction was observed for $30 \%$ pulp fibre in composite. The low-temperature compounding of HYP/PA11 presents higher shear viscosity compared to the high-temperature compounding for the same rheological parameters; this is because during the process the temperature was low and the mixing and melting were produced by the high shear rate created during compounding process. Experimental testing results from HYP/PA11 for the extrusion processing technique showed a steep decrease in shear viscosity with increasing shear rate at high temperature, and this melt-flow characteristic corresponds to shear thinning behavior in HYP/PA11 and due to the high pulp moisture content which tends to degrade polyamide 11. Results also showed high shear-thinning behavior in modified HYP/PA11 associated with a high degree of crystallinity and pseudoplasticity; this was due to the good dispersion of HYP into PA11 and the orientation of the flexible fibre effects in the direction of the molten PA11.

\section{Acknowledgements}

This work was carried out with the support of Mitacs funding, Automotive Partnership Canada $<\mathrm{APC}>$; the University of Toronto and the Ford Motor Company financially supported this study.

\section{References}

[1] Pervaiz, M. and Sain, M. (2003) Carbon Storage Potential in Natural Fibre Compos- 
ites. Resources, Conservation and Recycling, 39, 325-340.

[2] Bourmaud, A. and Baley, C. (2009) Rigidity Analysis of Polypropylene/Vegetal Fibre Composites after Recycling. Polymer Degradation and Stability, 39, 297-305.

[3] Sadeghian, N. and Golzar, M. (2008) PVT Measurement System for Wood Plastic Composite Melt in an Extrusion Process. Journal of Reinforced Plastics and Composites, 27, 739-750. https://doi.org/10.1177/0731684407084250

[4] Thomen, H. (2001) Modeling the Physical Processes in Natural Fiber Composites during Batch and Continuous Pressing. Thesis, Oregon State University, Corvallis.

[5] Gu, R. and Kokta, B. (2010) Mechanical Properties of PP Composites Reinforced with BCTMP Aspen Fiber. Journal of Thermoplastic Composite Materials, 23, 513 542. https://doi.org/10.1177/0892705709355232

[6] Bajpai, P. (2012) Brief Description of the Pulp and Paper Making Process. In: Bajpai, P., Ed., Biotechnology for Pulp and Paper Processing, Springer Science + Business Media, Berlin, 7-14. https://doi.org/10.1007/978-1-4614-1409-4_2

[7] Plackett, D., Torgilsson, R. and Andersen, T. (2010) Influence of Fiber Type, Fiber Mat Orientation, and Process Time on the Properties of a Wood Fiber/Polymer Composite. International Journal of Polymeric Materials, 51, 1005-1018. https://doi.org/10.1080/714975684

[8] Kaw, A. and Besterfield, G. (1998) Effect of Interphase on Mechanical Behaviour of Composites. Journal of Engineering Mechanics, 117, 2641-2658. https://doi.org/10.1061/(ASCE)0733-9399(1991)117:11(2641)

[9] Yeh, J.R. (1992) The Effect of Interphase on the Transverse Properties of Composites. International Journal of Solids and Structures, 29, 2493-2502.

[10] Gohil, P. and Shaikh, A. (2010) Analytical Investigation and Comparative Assessment of Interphase Influence on Elastic Behavior of Fiber Reinforced Composites. Journal of Reinforced Plastics and Composites, 29, 685-699. https://doi.org/10.1177/0731684408100268

[11] Kari, S., Berger, H., Rodriguez, R.R. and Gabbert, U. (2005) Computational Evaluation of Effective Material Properties of Composites Reinforced by Randomly Distributed Spherical Particles. Composite Structures, 71, 397-400.

[12] Lamnawar, K. and Maazouz, A. (2008) Rheology at the Interface and the Role of the Interphase in Reactive Functionalized Multilayer Polymers in Coextrusion Process. American Institute of Physics, 978, 7354-7549. https://doi.org/10.1063/1.2964771

[13] Larache, M., Agbossou, A. and Pastor, J. (1994) Role of Interphase on Elastic Behavior of Composite Materials: Theoretical and Experimental Analysis. Journal of Composite Materials, 28, 1141-1157.

[14] George, J., Sreekala, M.S. and Thomas, S. (2001) A Review on Interface Modification and Characterization of Natural Fiber Reinforced Plastic Composites. Polymer Engineering \& Science, 41, 1471-1485. https://doi.org/10.1002/pen.10846

[15] Liu, Y.J., Xu, N. and Luo, J.F. (2000) Modeling of Interphases in Fiber-Reinforced Composites under Transverse Loading Using Boundary Element Method. Journal of Applied Mechanics, 67, 41. https://doi.org/10.1115/1.321150

[16] Uhlherr, P.H.T., Guo, J., Zhang, X.M., Zhou, J.Z.Q. and Tiu, C. (2005) The ShearInduced Solid-Liquid Transition in Yield Stress Materials with Chemically Different Structures. Journal of Non-Newtonian Fluid Mechanics, 125, 101-119.

[17] Huq, A.M.R. and Azaiez, J. (2005) Effect of Length Distribution on the Steady Shear Viscosity of Semiconcentrated Polymer-Fiber Suspensions. Polymer Engineering \& Science, 45, 1357-1368. https://doi.org/10.1002/pen.20415

[18] Larson, R.G. (1999) The Structure and Rheology of Complex Fluids. Oxford Uni- 
versity Press, New York.

[19] Eberle, A. (2008) The Dynamic Behavior of a Concentrated Composite Fluid Containing Non-Brownian Glass Fibers in Rheometrical Flows. PhD Thesis, Virginia Tech., Blacksburg.

[20] Le Moine, N., Oever, M.V.D. and Budtova, T. (2013) Dynamic and Capillary Shear Rheology of Natural Fiber-Reinforced Composites. Polymer Engineering \& Science, 53, 2582-2593. https://doi.org/10.1002/pen.23521

[21] Guo, R., Azaiez, J. and Bellehumeur, C. (2005) Rheology of Fiber Filled Polymer Melts: Role of Fiber-Fiber Interactions and Polymer-Fiber Coupling. Polymer Engineering and Science, 45, 385-399. https://doi.org/10.1002/pen.20285

Submit or recommend next manuscript to SCIRP and we will provide best service for you:

Accepting pre-submission inquiries through Email, Facebook, LinkedIn, Twitter, etc. A wide selection of journals (inclusive of 9 subjects, more than 200 journals)

Providing 24-hour high-quality service

User-friendly online submission system

Fair and swift peer-review system

Efficient typesetting and proofreading procedure

Display of the result of downloads and visits, as well as the number of cited articles Maximum dissemination of your research work

Submit your manuscript at: http://papersubmission.scirp.org/

Or contact anp@scirp.org 